\title{
Caracterização física e química dos filitos Açungui (PR) visando sua utilização pela indústria cerâmica
}

\section{(Physical and chemical characteristics of Açungui phillites (PR, Brazil) for their use by ceramic industries)}

\author{
J. C. Biondi, E. S. Marczynski \\ Departamento de Geologia, Universidade Federal do Paraná, UFPR \\ C. P. 19.001 \\ Curitiba, PR 81.531-990 \\ jcbiondi@geologia.ufpr.br
}

\begin{abstract}
Resumo
O estudo de 12 amostras selecionadas de filitos do Açungui revelou serem rochas com sericita, caulinita, quartzo e goethita, sem smectitas e cloritas, localmente, com zeólitas sódicas. Suas cores de queima, entre creme claro e marron escuro, são diretamente relacionadas aos teores de $\mathrm{Fe}_{2} \mathrm{O}_{3}$. Seus teores médios são: $\mathrm{SiO}_{2}=60,20 \%, \mathrm{Al}_{2} \mathrm{O}_{3}=22,33 \%, \mathrm{Fe}_{2} \mathrm{O}_{3}=6,27 \%, \mathrm{~K}_{2} \mathrm{O}=3,84 \%, \mathrm{Na} \mathrm{O}_{2}=$ $1,09 \%$ e $\mathrm{TiO}_{2}=0,78 \%$. Têm teores de $\mathrm{S} \leq 760 \mathrm{ppm}, \mathrm{Zr} \leq 187 \mathrm{ppm}, \mathrm{Nb} \leq 41 \mathrm{ppm}, \mathrm{Y} \leq 29 \mathrm{ppm}, \mathrm{As} \leq 18 \mathrm{ppm}, \mathrm{Pb} \leq 33 \mathrm{ppm}, \mathrm{Cu} \leq 39 \mathrm{ppm}$ e Zn $\leq 47$ ppm. Após desagregados, a granulometria é $100 \%$ menor que $0,04 \mathrm{~mm}$, o diâmetro médio das partículas é 8,42 $\mu \mathrm{m}$, a média dos menores diâmetros é $6,82 \mu \mathrm{m}$ e a dos maiores é $13,20 \mu \mathrm{m}$. Os valores de $\alpha$ são $\geq 165 \mathrm{~cm} \mathrm{x} 10^{-7} /{ }^{\circ} \mathrm{C}$ e separam os filitos em um grupo com $\alpha<205 \mathrm{~cm} \mathrm{x} 10^{-7} /{ }^{\circ} \mathrm{C}$ e outro $\operatorname{com} \alpha>208 \mathrm{~cm} \mathrm{x} 10^{-7} /{ }^{\circ} \mathrm{C}$. O $\alpha$ médio é 200,5 . A média das temperaturas do final da fase de dilatação é $833,7^{\circ} \mathrm{C}$, das perdas ao fogo é $5,42 \%$, das retrações lineares pós-queima é -14,0\%, das taxas de absorção de água pósqueima é $1,00 \%$, das resistências à flexão dos corpos de prova cru é $3,0 \mathrm{Kgf} / \mathrm{cm}^{2}$ e pós-queima é $80 \mathrm{Kgf} / \mathrm{cm}^{2}$. Há dois tipos de filitos: (a) os com teores de $\mathrm{Na}_{2} \mathrm{O}$ maiores que $0,8 \%, \alpha$ maiores que $208 \mathrm{~cm} \mathrm{x} 10^{-7} /{ }^{\circ} \mathrm{C}$ e com zeólitas e, (b) os com menos que $0,25 \%$ de $\mathrm{Na}_{2} \mathrm{O}$, $\alpha$ menores que $205 \mathrm{~cm} \mathrm{x} 10^{-7} /{ }^{\circ} \mathrm{C}$ e sem zeólita. As cores de queima escuras, os elevados índices de dilatação e de retração e baixos índices de resistência mecânica à flexão pós-queima limitam o uso dessas rochas em massas cerâmicas, onde poderiam ser aproveitadas somente como fundentes.
\end{abstract}

Palavras-chave: filitos, Açungui (PR), propriedades químicas, físicas e cerâmicas.

\begin{abstract}
Analysis of 12 samples of Açungui phyllites showed rocks composed by sericite, kaolinite, quartz and goethite, without smectites and chlorites, and locally with sodiam zeolites. Their tones upon fire vary from white cream to dark brown and are directly related to $\mathrm{Fe}_{2} \mathrm{O}_{3}$ grades. The average grades are: $\mathrm{SiO}_{2}=60.20 \%, \mathrm{Al}_{2} \mathrm{O}_{3}=22.33 \%, \mathrm{Fe}_{2} \mathrm{O}_{3}=6.27 \%, \mathrm{~K}_{2} \mathrm{O}=3.84 \%, \mathrm{Na}_{2} \mathrm{O}=1.09 \%$ e $\mathrm{TiO}_{2}=0.78 \% . \mathrm{S}$ grades are $\leq 760 \mathrm{ppm}, \mathrm{Zr} \leq 187 \mathrm{ppm}, \mathrm{Nb} \leq 41 \mathrm{ppm}, \mathrm{Y} \leq 29 \mathrm{ppm}, \mathrm{As} \leq 18 \mathrm{ppm}, \mathrm{Pb} \leq 33 \mathrm{ppm}, \mathrm{Cu} \leq 39 \mathrm{ppm}$ and $\mathrm{Zn} \leq 47 \mathrm{ppm}$. After disaggregated, their granulation is $100 \%$ smaller than $0.04 \mathrm{~mm}$, the average diameter of all particles is $8.42 \mu \mathrm{m}$, the average diameter of the smallest particle is $6.82 \mu \mathrm{m}$ and of the largest is $13.20 \mu \mathrm{m}$. The \pm stretching values are $\geq 165 \mathrm{~cm} \times 10^{-7} /{ }^{\circ} \mathrm{C}$ and they separate one group of phyllites with $\alpha<205 \mathrm{~cm} \times 10^{-7} /{ }^{\circ} \mathrm{C}$ and another with $\alpha>208 \mathrm{~cm} \times 10^{-7} /{ }^{\circ} \mathrm{C}$. The average $\alpha$ value is 200.5 . The final stretching average temperature is $833.7{ }^{\circ} \mathrm{C}$. The average loss on ignition is $5.42 \%$, of linear shrinkage at $1220^{\circ} \mathrm{C}$ is $-14.0 \%$, of water absorption is $1.00 \%$, of flexural strength before firing is $3.0 \mathrm{Kgf} / \mathrm{cm}^{2}$ and is $80 \mathrm{Kgf} / \mathrm{cm}^{2}$ after firing. There are two major phyllite types: (a) those with $>0.8 \% \mathrm{Na}_{2} \mathrm{O}, \alpha$ greater than $208 \mathrm{~cm} \times 10^{-7} /{ }^{\circ} \mathrm{C}$ and with $\mathrm{Na}$ zeolites and, (b) those with $<0.25 \% \mathrm{Na}_{2} \mathrm{O}$, $\alpha$ smaller than $205 \mathrm{~cm} \times 10^{-7} /{ }^{\circ} \mathrm{C}$ and without zeolites. The dark tones upon firing, high stretching and shrinkage index and low values of flexural strength after firing, confine the use of these rocks on ceramic compositions, pointing out to their use only as flux material.

Keywords: phyllite, Açungui (PR, Brazil), chemistry, physical and ceramic properties.
\end{abstract}

\section{INTRODUÇÃO}

Filitos cerâmicos são rochas metamórficas que, moídas, são usadas em massas de grês sanitário, como substitutos parciais de argilas e de feldspatos. São, também, utilizados, em várias proporções, para aumentar a velocidade de sinterização de massas de faianças para louças de mesa, em ladrilhos de piso, em azulejos, em alguns materiais refratários e em cerâmicas elétricas [1]. Devido a conterem minerais com potássio e sódio, têm atuação importante como fundentes [2], substituindo o feldspato. Em 2002 foi estimado que a produção brasileira de filito foi de $653.000 \mathrm{t}$ [3], lavrado principalmente em Itapeva (SP) e Divinópolis/Igarapé (= ardósias de Minas Gerais), para abastecer o pólo cerâmico de Santa Gertrudes, e em Campo Largo (PR), para as indústrias cerâmicas locais. Ocasionalmente são utilizados para o fabrico de telhas.

Os filitos são rochas muito comuns constituindo-se em matérias primas cerâmicas de baixo valor, o que inviabiliza o 
seu uso quando a distância entre a mina e a indústria for grande. $\mathrm{O}$ objetivo deste trabalho é mostrar as principais características cerâmicas dos filitos existentes no Estado do Paraná, onde ocorrem em várias regiões, além de Campo Largo, e em grandes quantidades.

\section{MATERIAIS E MÉTODOS}

\section{Área de ocorrência e coleta das amostras}

Os filitos do Grupo Açungui afloram em uma faixa irregular e descontínua orientada NW, com cerca de $35 \mathrm{~km}$ de largura, que estende-se desde a região de Campo Largo, ao lado de Curitiba (Fig. 1), até a região de Itapeva, em São Paulo. No Estado de São Paulo, outra faixa de filitos semelhantes aos do Açungui faz parte do Grupo São Roque. Os filitos São Roque afloram desde a divisa entre Paraná e São Paulo até a região ao norte da cidade de São Paulo. No total, essas as faixas cobrem uma área de cerca de $8000 \mathrm{Km}^{2}$.

Para este estudo foram coletadas 30 amostras em quatro regiões diferentes (Fig. 1, regiões A, B, C e D), cada uma com 2 a $5 \mathrm{~kg}$, compostas por vários fragmentos retirados de barrancos ao lado de rodovias de tráfego permanente, próximas a Rio Branco do Sul, cidade situada $25 \mathrm{Km}$ a norte de Curitiba. Dentre as 30 amostras coletadas foram selecionadas 12, das regiões B (7 amostras), C (2 amostras) e D (3 amostras), com cores mais claras e granulação mais fina (Tabela III).

\section{Análises químicas}

As amostras foram moídas em moinho de mandíbula e quarteadas, separando duas alíquotas de cerca de $100 \mathrm{~g}$ de cada amostra. Uma alíquota de cada amostra foi pulverizada em moinho de anéis até ter sua granulometria toda menor que 0,074mm (200 mesh). Um novo quarteamento separou uma fração de $0,9 \mathrm{~g}$ que foi misturada a 9,0 g de tetraborato de lítio e fundida em uma fusora Claysse 30 . O vidro produto da fusão foi resfriado em uma forma de Pt-Au, gerando uma pastilha de $40 \mathrm{~mm}$ de diâmetro e $3 \mathrm{~mm}$ de espessura. Esta pastilha foi analisada por flurescência de raios X em um equipamento Philips PW 2400 (LAMIR-UFPR). Os resultados estão na Tabela I.

\section{Análises mineralógicas}

As segundas alíquotas das amostras foram desagregadas em moinho de jarra, com bolas cerâmicas, em meio líquido (água destilada e desmineralizada), durante 30 minutos. As suspensões obtidas foram postas em provetas com $50 \mathrm{~cm}$ de altura e deixadas em repouso por uma hora. Após sedimentarem, foram pipetadas cerca de $50 \mathrm{~mL}$ das suspensões que ficaram nas partes superiores das provetas. O líquido pipetado em cada proveta foi posto para precipitar em placas de Petri nas quais havia três lâminas de vidro de 2,5 por $5,0 \mathrm{~cm}$. Dessas três lâminas, uma foi deixada sem tratamento, outra foi queimada a $500{ }^{\circ} \mathrm{C}$ por duas horas e a terceira foi molhada com glicol-etileno durante 12 horas. Além dessas três lâminas, foi feito também um esfregaço para cada amostra. Foram feitas difratogramas de raios $\mathrm{X}$ das quatro lâminas de cada amostra (3 precipitadas + esfregaço) com um aparelho Philips PW 1800 (LAMIR-UFPR). Os resultados estão expressos na Fig. 2A-D.

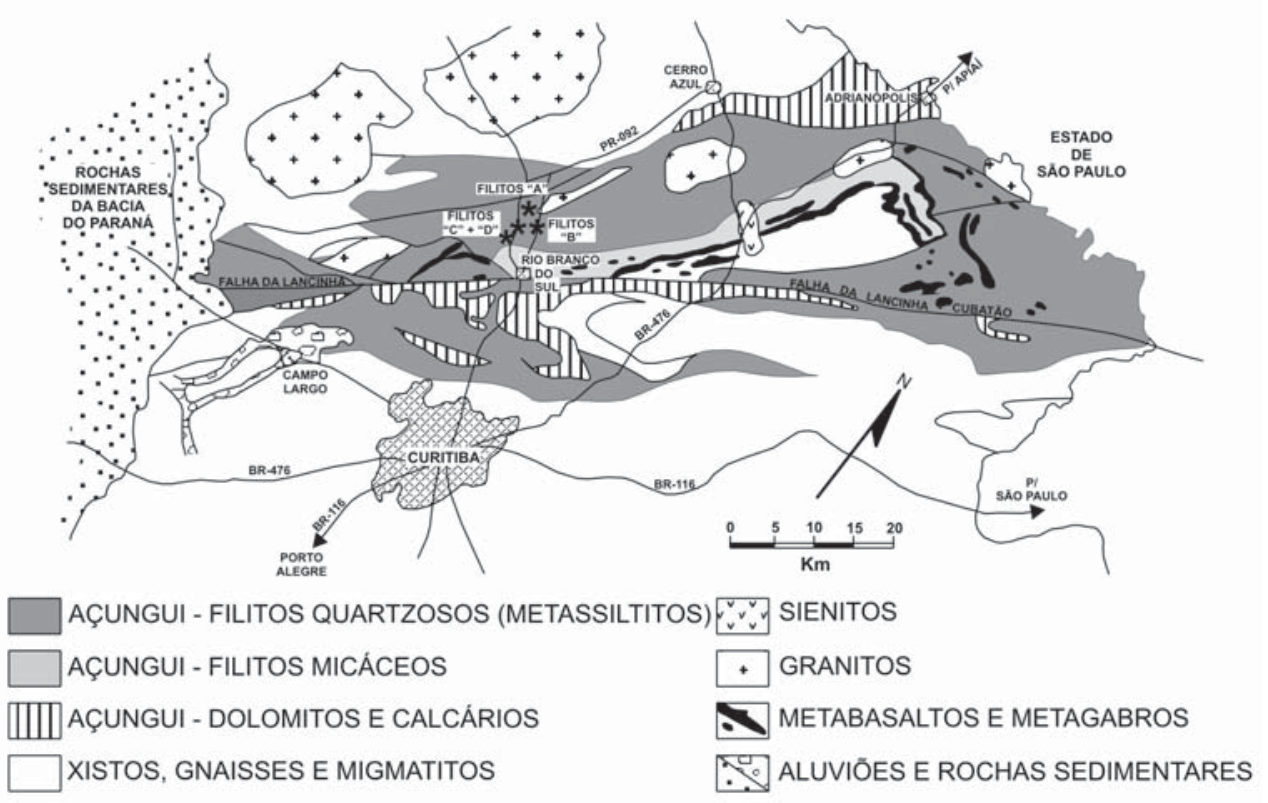

Figura 1: Mapa geológico-geográfico simplificado mostrando as regiões de ocorrência de filitos no Estado do Paraná. Notar, a NW da cidade de Rio Branco do Sul, os sinais (*), a lado dos textos "filitos B" e "filitos C + D", indicando os locais onde foram coletadas as amostras usadas nesse estudo.

[Figure 1: Geologic and geographic simplified map of Paraná State showing regions where Açungui phyllite outcrops. Signals (*) NW from Rio Branco do Sul City are places where studied samples were collected.] 


\section{Análises granulométricas}

Após feitas as pipetagens das suspensões contidas nas provetas, elas foram agitadas, as suspensões foram homogeneizadas e postas a secar sob ventilação forçada. Após a secagem, cada amostra foi postas em uma pilha de 5 peneiras de aço com malhas entre 0,5 e $0,04 \mathrm{~mm}$ e vibradas por 30 minutos. Com este procedimento as amostras foram desagregadas e homogeneizadas. A fração retida no fundo da pilha foi quarteada até obter uma fração de cerca de $20 \mathrm{~g}$ de cada amostra. De cada fração quarteada foram separadas três sub-frações com cerca de $1,0 \mathrm{~cm}^{3}$ cada, que foram analisadas com um granulômetro a laser CILAS 1064L, em suspensão aquosa. Foram feitas 20 medidas em cada uma das sub-frações, o que produziu 60 medidas granulométricas em cada amostra. Foram determinadas as médias de cada medida e os resultados foram expressos em histogramas, em curvas de freqüência acumulada (Fig. 3) e sob forma numérica (Tabelas II e III).

\section{Ensaios cerâmicos}

Com o material obtido após a desagregação no moinho de jarra, foram feitos ensaios cerâmicos segundo os procedimentos que constam na norma ABNT-NBR 13818. Os ensaios realizados foram: perda ao fogo, dilatação linear (dilatômetro BP 3000), retração linear pós-queima $\left(122{ }^{\circ} \mathrm{C}\right)$, absorção de água pósqueima $\left(1220^{\circ} \mathrm{C}\right)$, tensão de ruptura à flexão a cru e pós-queima a $1220^{\circ} \mathrm{C}$ (flexurômetro BP 50). Os resultados estão expressos na Figs. 3, 4 (dilatação linear) e na tabela III.

\section{RESULTADOS}

\section{Análises químicas}

Os filitos do Açungui são rochas sílico-aluminosas com teores elevados de álcalis, ferro e titânio (Tabela I). Os teores médios são: $\mathrm{SiO}_{2}=60,20 \%(\mathrm{~s}=2,25 \%), \mathrm{Al}_{2} \mathrm{O}_{3}=22,33 \%$
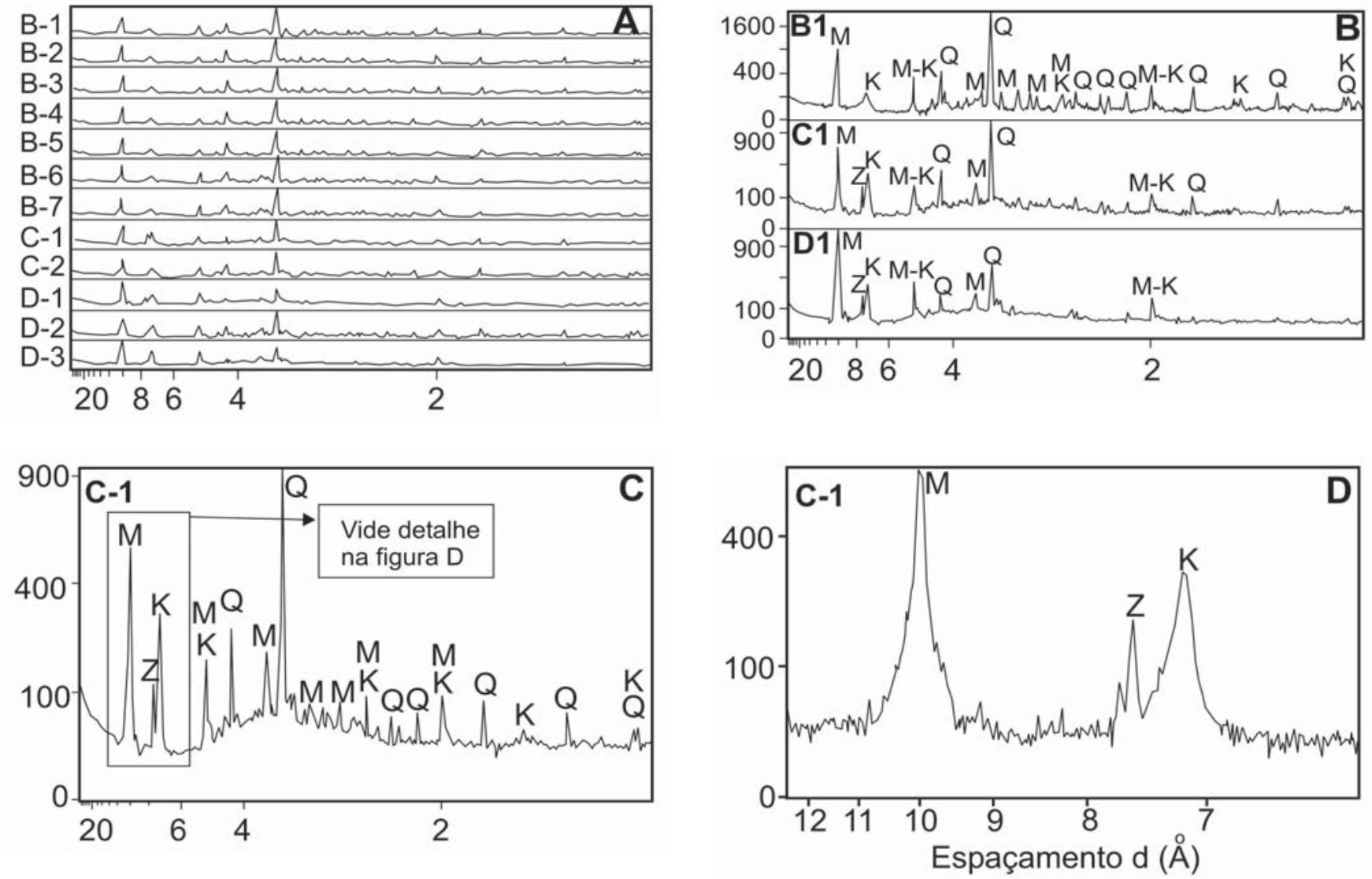

Figura 2: (A) Difratogramas de raios X das frações finas de todas as amostras de filito, precipitadas sobre lâminas de vidro (parte que ficou em suspensão nas provetas). As raias estão identificadas na Fig. C. (B) Há dois tipos diferentes de filitos: (a) os tipo B-1, coletados na área B (Fig. 1), com quartzo (Q), muscovita (M), caulinita (K) e goethita. A goethita precipita nas provetas e não aparece nesses difratogramas. (b) Os tipo C-1 ou D-1, com menos quartzo e mais muscovita que os tipo B. As raias estão identificadas na Fig. C. (C) As amostras C-1 e D-1 têm raias entre 7,2 e 7,3 Å que indicam a presença de zeólitas. (D) Detalhe da parte do difratograma da amostra C-1, entre 7,0 $\AA$ e $12,0 \AA$, tornando mais visíveis as raias indicadoras da presença de zeólitas $(\mathrm{Z})$.

[Figure 2: (A) X-ray (001) diffraction of all studied samples. Strips are matched on Fig. $C$. (B) There are two phyllite types: (a) B-1 type, sampled on $B$ area (Fig. 1), with quartz (Q), muscovite $(M)$, kaolinite $(K)$ and goethite. Goethite precipitates before samples used to make (001) precipitates were collected. (b) C-1 and D-1 types with less quartz and more muscovite than B ones. Strips are matched on Fig. C. (C) C-1 and D-1 samples have X-ray strips between 7,2 and 7,3 A typical of Na-zeolites. (D) C-1 X-ray diffraction detail, between 7,0 and 12,0 $\AA$, showing strips that identify Na-zeolites.] 
( $\mathrm{s}=1,63 \%), \mathrm{Fe}_{2} \mathrm{O}_{3}=6,27 \%(\mathrm{~s}=2,07 \%), \mathrm{K}_{2} \mathrm{O}=3,84 \%$ ( $\mathrm{s}=0,59 \%), \mathrm{Na}_{2} \mathrm{O}=1,09 \%(\mathrm{~s}=0,54 \%)$ e $\mathrm{TiO}_{2}=0,78 \%$ ( $\mathrm{s}=0,05 \%)$. Têm teores de $\mathrm{S}$ muito variados, entre $<1$ e 760 ppm, baixos teores de $\mathrm{Zr}(\leq 187 \mathrm{ppm}), \mathrm{Nb}(\leq 41 \mathrm{ppm})$ e $\mathrm{Y}$ ( $\leq 29 \mathrm{ppm})$. Os teores de As ( $\leq 18 \mathrm{ppm}), \mathrm{Pb}(\leq 33 \mathrm{ppm}), \mathrm{Cu}$ $(\leq 39 \mathrm{ppm})$ e $\mathrm{Zn}(\leq 47 \mathrm{ppm})$ são relativamente elevados, considerando os teores máximos admitidos para cerâmicas de mesa. Os teores de $\mathrm{Rb}(\leq 282 \mathrm{ppm})$ e de $\mathrm{Ba}(\leq 742)$ são também elevados, mas não são elementos deletérios para o uso cerâmico.

\section{Análise mineralógicas}

Os filitos Açungui são compostos por quartzo, muscovita, caulinita e goethita (Figs. 2A e B). As amostras coletadas nas áreas $\mathrm{C}$ e $\mathrm{D}$ (Fig. 1) têm menos quartzo e mais muscovita que os da área $\mathrm{B}$, conforme indicado pelas alturas relativas das raias diagnósticas desses minerais (Fig. 2B). As lâminas sem tratamento e tratadas com glicol-etileno das mostras $\mathrm{C}-1$ e D-1 têm raias entre 7,2 e 7,3 $\mathrm{A}$, ao lado da raia principal da caulinita (Figs. 2B, $\mathrm{C}$ e D). Estas raias não aparecem nos difratogramas feitos com as lâminas queimadas a $500{ }^{\circ} \mathrm{C}$, o que indica que estas raias sejam de zeólitas, provavelmente ferrinatrita $\left[\mathrm{Na}_{2}\left(\mathrm{Al}_{2} \mathrm{Si}_{3} \mathrm{O}_{10}\right) \cdot 2 \mathrm{H}_{2} \mathrm{O}\right]$ e/

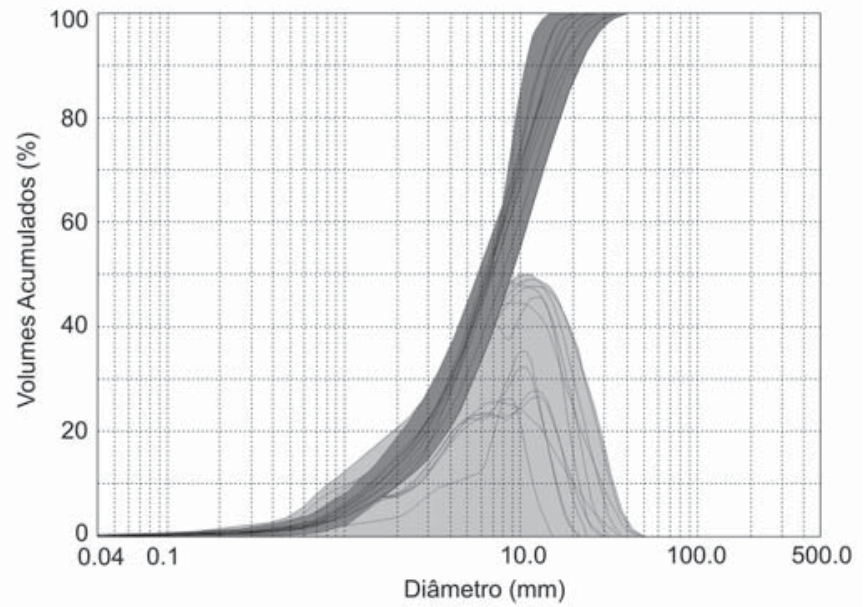

Figura 3: Curvas de freqüência acumulada e histogramas médios das granulometrias de 12 amostras analisadas com granulômetro a laser. As distribuições das freqüências acumuladas são pouco variadas. A maior parte dos histogramas é bimodal.

[Figure 3: Granulometric cumulative probability plots and histograms of 12 samples analysed by laser diffraction. Shapes of cumulative plots are similar. The major part of samples has bimodal histograms.]

\section{Todas as amostras}
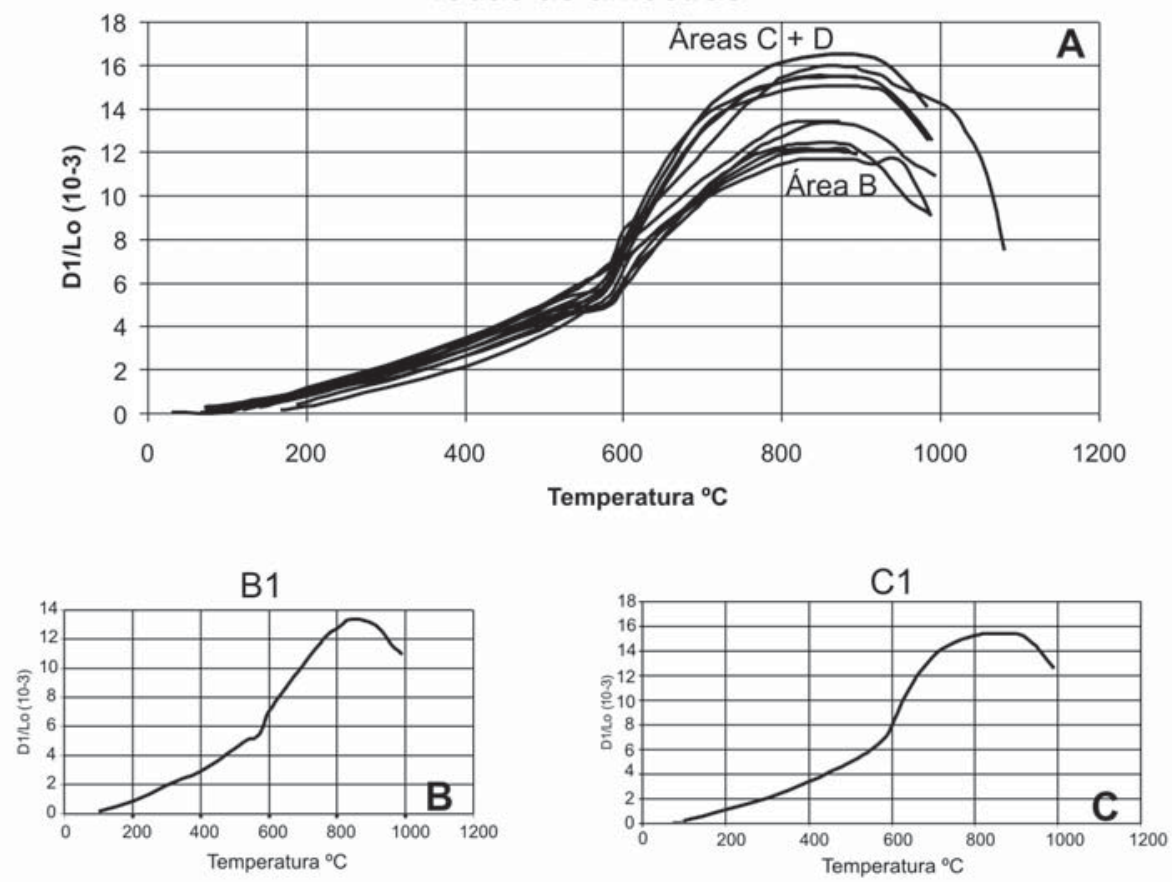

Figura 4: Curvas de evolução da dilatação linear dos filitos Açungui. (A) A superposição de todas as curvas mostra que as inclinações médias ( \pm ) das amostras da área B são menores que as das área C e D. (B) A forma arredondada do final da curva de dilatação dos filitos "tipo B" indicam que tenham mais caulinita e quartzo que os "tipos C e D". (C) O patamar no final da curva de dilatação dos filitos "tipo C e D” indicam a composição micácea desses filitos.

[Figure 4: Stretching values diagram of Açungui phyllites. (A) The overlap of all stretching curves shows that \pm of B region's sample are smaller than $C$ and $D$ ones. $(B)$ The round form of the end of the stretching curves of "type B" samples suggests that they have more sericite and kaolinite than "type $C$ and D" samples. $(C)$ The sill at the end of "type $C$ and D" curves suggests that mica is their main mineral.] 


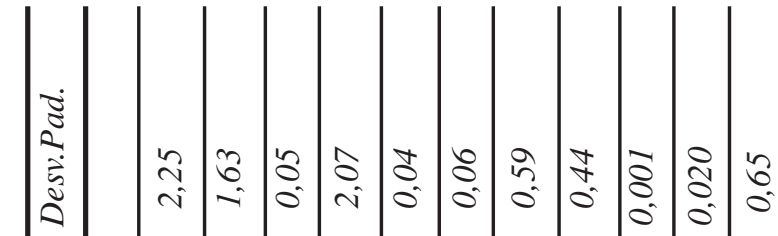

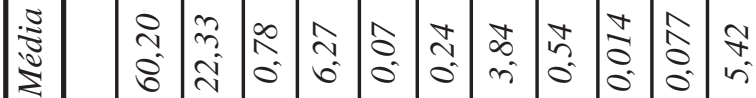

(1)

$\stackrel{8}{2}$

需

范

苞

เี้

$\exists=$

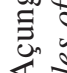

ڤ

吾

요

象

\&

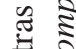

要

卷.

हु

音

호

.

:

20

先

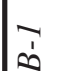

n

กิ

อิ

ù

ú

î

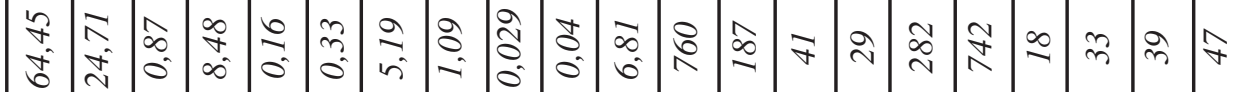

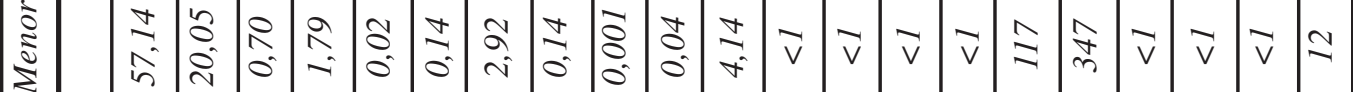

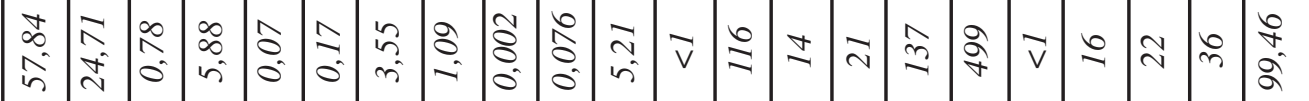

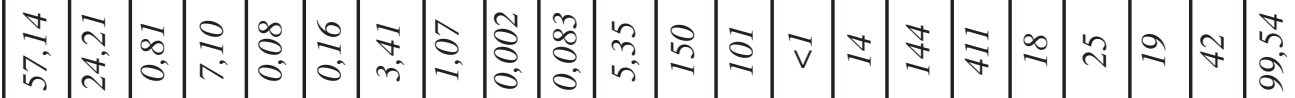

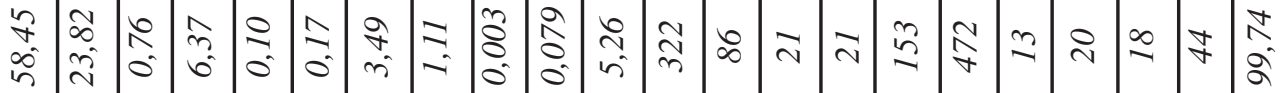

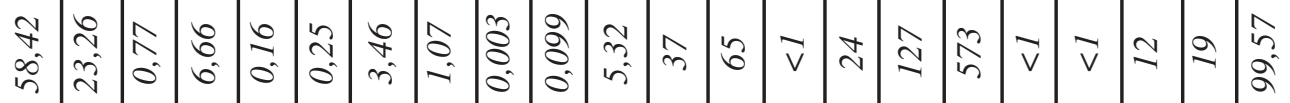

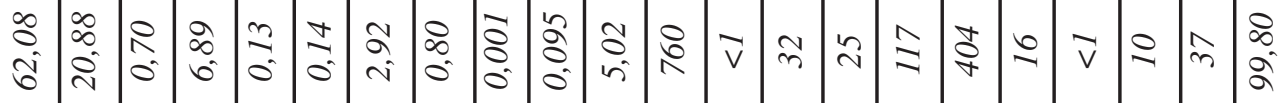

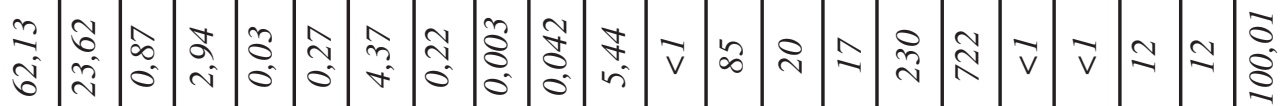

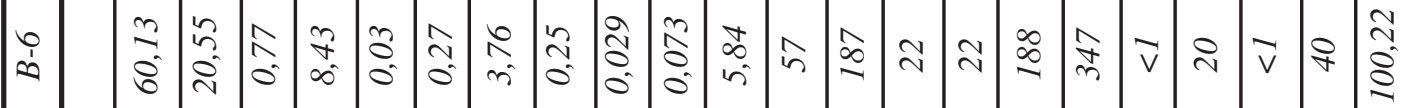

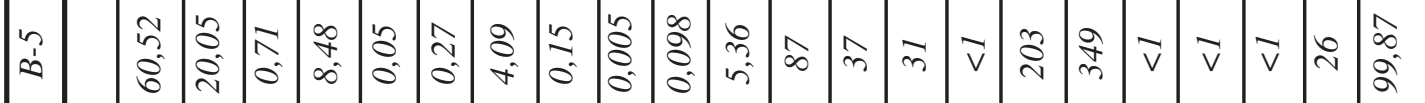

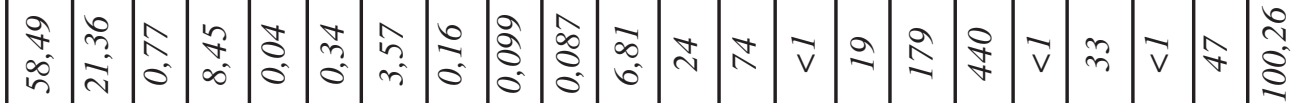

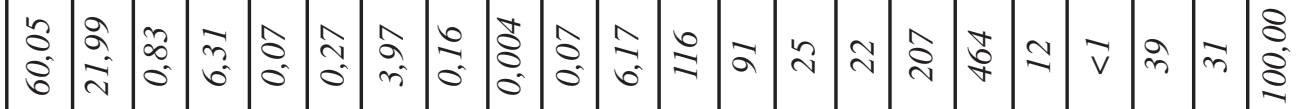

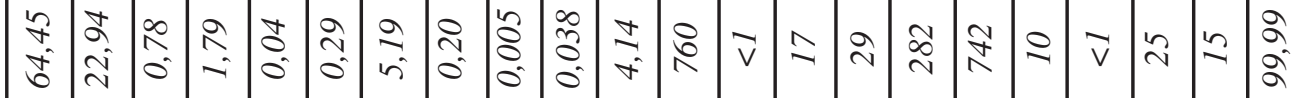

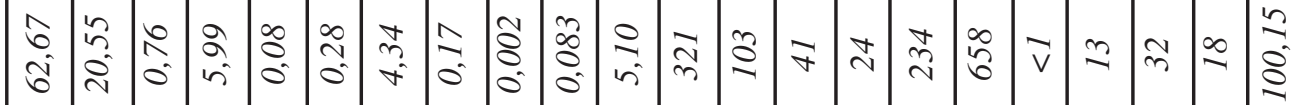

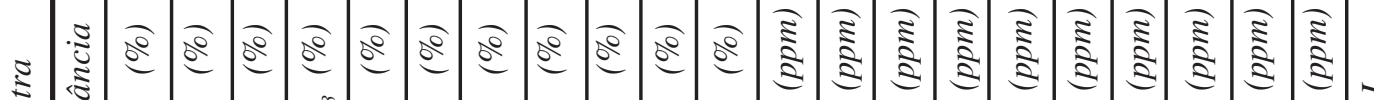

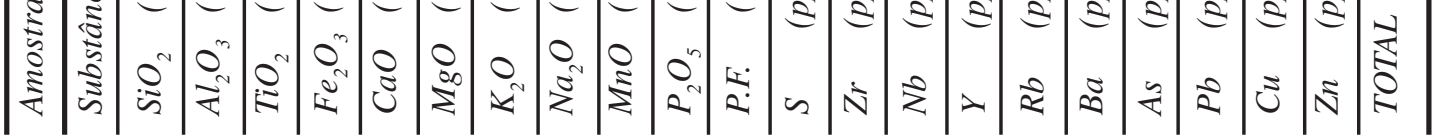


Tabela II - Diâmetros médios e percentagens em volume ocupados pelas partículas que compõem os filitos da Formação Votuverava, Grupo Açungui (PR), determinados com granulômetro a laser.

[Table II - Average particle diameter and volume (laser granulometer) of phillites from Açungui (PR)

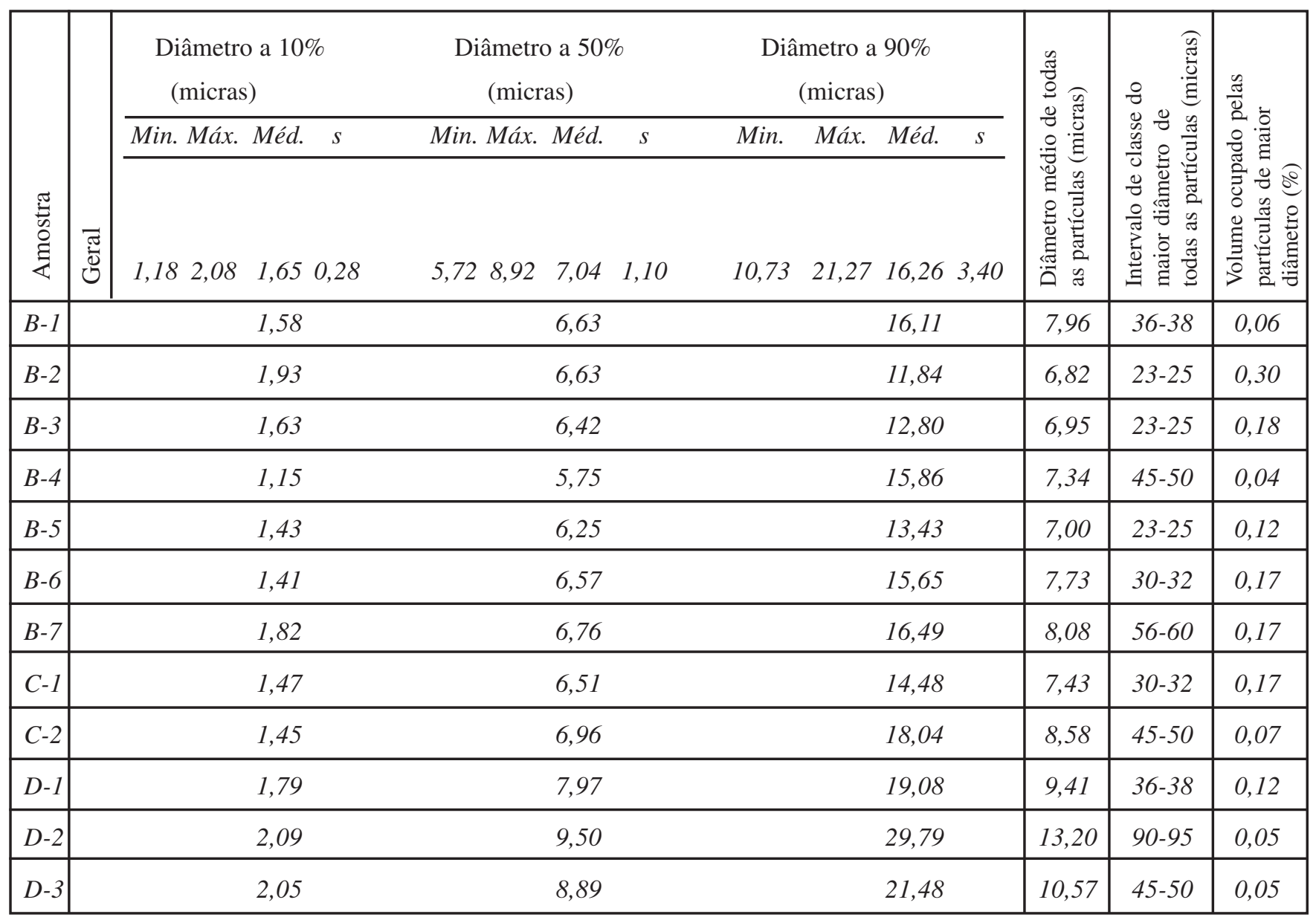

Diâmetro médio das partículas do filtro $=8,42 \mu \mathrm{m}$

Desvio padrão da medida do diâmetro $=1,78 \mu \mathrm{m}$

Menor diâmetro médio medido nas amostras analizadas $=6,82 \mu \mathrm{m}$

Maior diâmetro médio medido nas amostras analizadas $=13,20 \mu \mathrm{m}$

ou gmelinita $\left[\left(\mathrm{Na}_{2}, \mathrm{Ca}\right)\left(\mathrm{Al}_{2} \mathrm{Si}_{4} \mathrm{O}_{12}\right) \cdot 6 \mathrm{H}_{2} \mathrm{O}\right]$, minerais hidratados e instáveis a tratamento térmico.

\section{ENSAIOS CERÂMICOS}

\section{Análises granulométricas}

Após desagregados nos moinhos de jarra, todas as amostras ficaram com granulometria 100\% menor que 0,04 mm (325 mesh). As 12 curvas de frequência acumulada e os histogramas da Fig. 3 são médias de 60 medidas feitas com granulômetro a laser em cada amostra.

Na Tabela II são mostrados os diâmetros mínimos, máximos e médios das partículas acumuladas nos percentis 10, 50 e 90. Considerando as 12 amostras analisadas, o menor diâmetro identificado foi $1,18 \mu \mathrm{m}$ e o maior está no intervalo entre 90 e $95 \mu \mathrm{m}$. Considerando todas as 12 amostras, o diâmetro médio das partículas é $8,42 \mu \mathrm{m}$ ( $\mathrm{s}=1,78 \mu \mathrm{m})$, a média dos menores diâmetros é 6,82 $\mu \mathrm{m}$ e a dos maiores é $13,20 \mu \mathrm{m}$. As distribuições granulométricas de todas as amostras é pouco variada (Fig. 3) e várias amostras são bimodais, com uma moda entre 5 e $6 \mu \mathrm{m}$ e outra entre 10 e $20 \mu \mathrm{m}$.

\section{Análises dilatométricas}

As curvas de evolução da dilatação linear das 12 amostras analisadas constam na Fig. 4A, e os valores de dilatação térmica média $(\alpha)$ e das temperaturas do final da fase de dilatação de cada amostra estão listados na Tabela III. Todas as amostras têm valores de $\alpha$ elevados, $\geq 165 \mathrm{~cm} \mathrm{x} 10^{-7} /{ }^{\circ} \mathrm{C}$. Os valores de $\alpha$ separam as amostras em dois grupos distintos: (a) Os filitos da área B (Figs. 1 e 4A e B) têm valores de $\alpha$ menores que $205 \mathrm{~cm} \mathrm{x} 10^{-7} /{ }^{\circ} \mathrm{C}$. (b) Os das área $\mathrm{C}$ e D têm $\alpha$ maiores que $208 \mathrm{~cm} \mathrm{x} 10^{-7} /{ }^{\circ} \mathrm{C}$ (Figs. 1 e $4 \mathrm{~A}$ e C). $\mathrm{O} \alpha$ médio de todas as amostras é $200,5 \mathrm{~cm} \mathrm{x} 10^{-7} /{ }^{\circ} \mathrm{C}$, com s $=25,6 \mathrm{~cm}$ $\mathrm{x} 10^{-7} /{ }^{\circ} \mathrm{C}$. As temperaturas do final da fase de dilatação são elevadas, variando entre 800 e $870{ }^{\circ} \mathrm{C}$ (média $=833,7^{\circ} \mathrm{C}$, $\left.\mathrm{s}=21,2^{\circ} \mathrm{C}\right)$. 


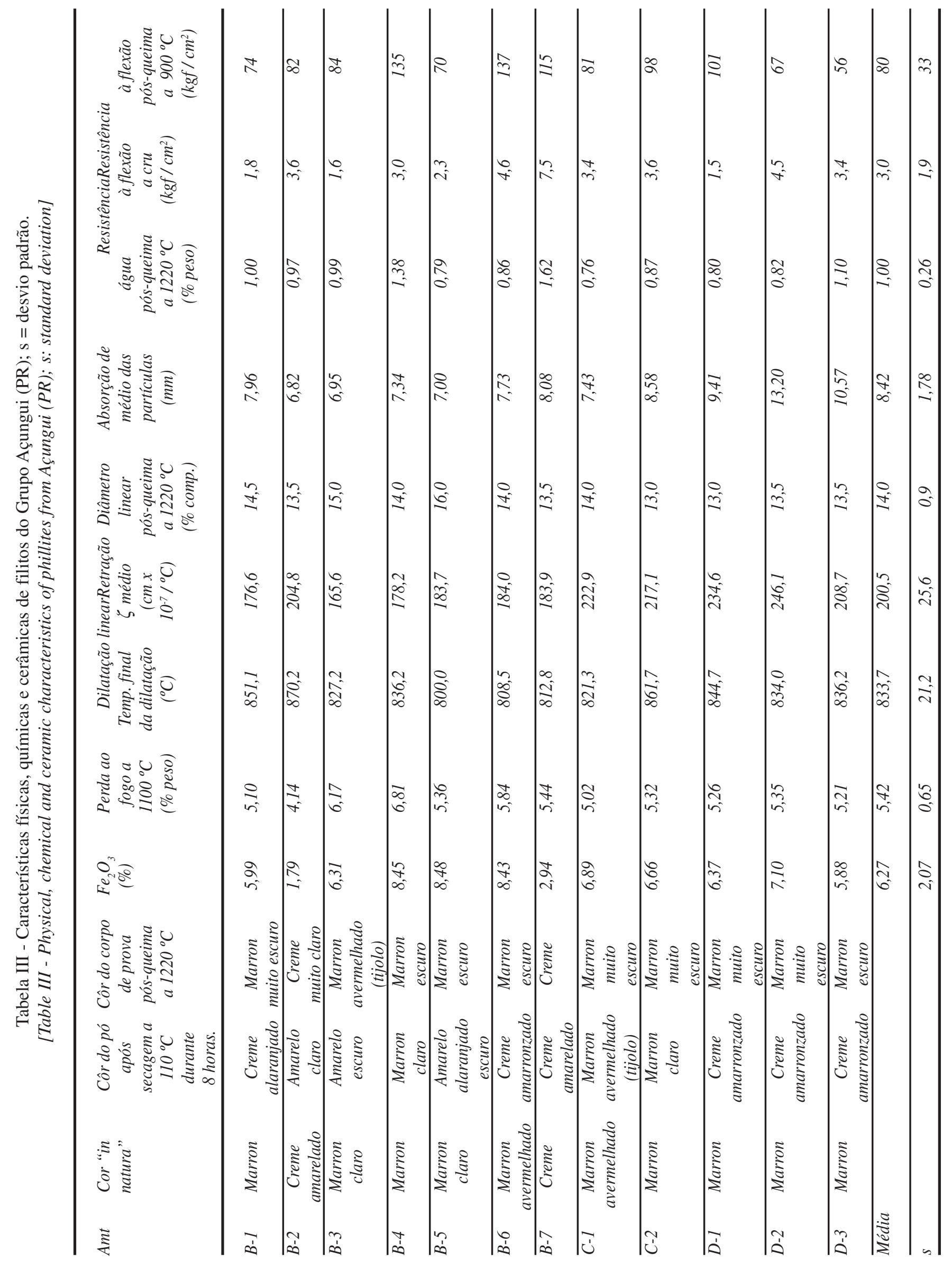




\section{Outros ensaios}

As cores "in natura" dos filitos Açungui variam entre o preto (filitos grafitosos) e o branco, predominando cores marron-avermelhadas e marron. Das 30 amostras coletadas, foram selecionadas as 12 mais claras, com cores próximas ao marron (Tabela III, primeira coluna), por serem os tipos
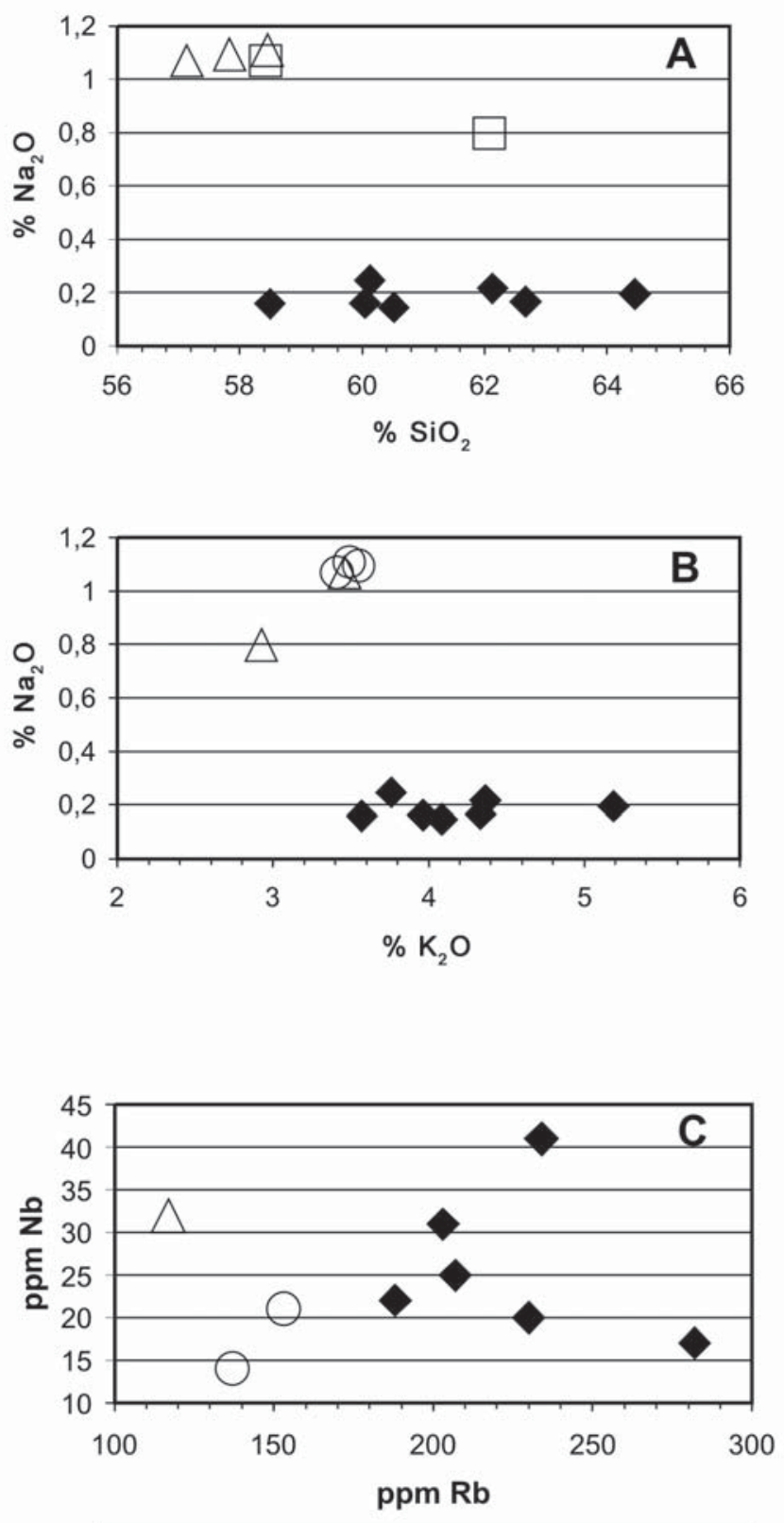

$\bullet$ Filitos tipo B $\triangle$ Filitos tipo C Filitos tipo D

Figura 5: Diagramas de dispersão de teores de filitos Açungui que diferenciam amostras coletadas na área $\mathrm{B}$ daquelas das áreas $\mathrm{C}$ e D. Diagramas: (A) $\mathrm{SiO}_{2}$ vs. $\mathrm{Na}_{2} \mathrm{O}$; (B) $\mathrm{K}_{2} \mathrm{O}$ vs. $\mathrm{Na}_{2} \mathrm{O}$ e, (C) $\mathrm{Nb}$ vs $\mathrm{Rb}$. [Figure 5: Scattering diagrams of Açungui phyllites chemical grades that discriminate samples from $B$ and $C+D$ areas. Diagrams: $(A)$ $\mathrm{SiO}_{2}$ vs. $\mathrm{Na}_{2} \mathrm{O}$; (B) $\mathrm{K}_{2} \mathrm{O}$ vs. $\mathrm{Na}_{2} \mathrm{O}$ e, (C) $\mathrm{Nb}$ vs Rb.] predominantes e mais representativos. Após desagregadas no moinho de jarra, secas e novamente desagregadas durante o peneiramento, no geral as cores tornaram-se mais claras (Tabela III, segunda coluna), variando entre o amarelo claro e o marron avermelhado. A queima a $1220^{\circ} \mathrm{C}$ dos corpos de prova, ao contrário, resultou em cores mais escuras que as das amostras pulverizadas, variando entre o creme muito claro e o marron muito escuro (Tabela III, terceira coluna).

As perdas ao fogo variam entre 4,14 e $6,81 \%$ em peso, com média igual a $5,42 \%(\mathrm{~s}=0,65 \%)$, as retrações lineares pósqueima variam entre $-13,5$ e $-16 \%$ do comprimento inicial, com média $=-14,0 \%(s=-0,9 \%)$, as taxas de absorção de água pósqueima variam entre 0,76 e $1,62 \%$ em peso, com média $=1,00 \%$ $(\mathrm{s}=0,26 \%)$, a resistência à flexão dos corpos de prova antes da queima variam entre 1,5 e 7,5 Kgf $/ \mathrm{cm}^{2}$, com média = 3,0 Kgf $/ \mathrm{cm}^{2}$ $\left(\mathrm{s}=1,9 \mathrm{Kgf} / \mathrm{cm}^{2}\right)$ e pós-queima a $900{ }^{\circ} \mathrm{C}$ entre 56 e $137 \mathrm{Kgf} /$ $\mathrm{cm}^{2}$, com média $=80 \mathrm{Kgf} / \mathrm{cm}^{2}\left(\mathrm{~s}=33 \mathrm{Kgf} / \mathrm{cm}^{2}\right)$.

\section{DISCUSSÃO}

Composição química dos filitos Açungui vs. minérios assemelhados

Composicionalmente os filitos Açungui diferenciam-se somente pelos seus teores de $\mathrm{Na}_{2} \mathrm{O}, \mathrm{K}_{2} \mathrm{O}$ e $\mathrm{Rb}$. No diagrama $\mathrm{SiO}_{2}$ vs. $\mathrm{Na}_{2} \mathrm{O}$, para teores de $\mathrm{SiO}_{2}$ entre 57 e $65 \%$ os teores de $\mathrm{Na}_{2} \mathrm{O}$ separam as amostras coletadas na região B (Fig. 1), com menos de $0,30 \%$, daquelas das regiões $\mathrm{C}$ e $\mathrm{D}$, com mais de $0,80 \%$ (Fig. $5 \mathrm{~A}$ ). No diagrama $\mathrm{Na}_{2} \mathrm{O}$ vs. $\mathrm{K}_{2} \mathrm{O}$, os filitos da região $\mathrm{B}$ têm mais que $3,60 \%$ de $\mathrm{K}_{2} \mathrm{O}$ (Fig. 5B) e no diagrama $\mathrm{Nb}$ vs. Rb mais que 180 ppm de Rb (Fig. 5C). Os teores de $\mathrm{Zr}$, $\mathrm{Y}$ e $\mathrm{Nb}$, elementos imóveis durante o intemperismo, das amostras das três áreas, variam dentro da mesma faixa (Fig. $5 \mathrm{C}$ e Tabela I), indicando que os sedimentos originais que geraram estas rochas tiveram as mesmas áreas fonte. As variações dos teores dos elementos mais móveis ( $\mathrm{Na}, \mathrm{K}$ e Rb) quando comparadas aos elementos imóveis indicam que as amostras coletadas têm taxas de intemperismo diferentes. Os teores de As são baixos, mas os de $\mathrm{Pb}, \mathrm{Cu}, \mathrm{Zn}$ e $\mathrm{S}$ de algumas amostras ultrapassam os limites tolerados em cerâmica de mesa (20 ppm)

Na Fig. 6 as composições dos filitos Açungui são comparadas às dos filitos Itapeva [4], às ardósias de Minas Gerais [5], aos sedimentos da Formação Corumbataí, de onde provêm os minérios usados nas indústrias da região de Santa Gertrudes [6, 7], e a quatro tipos de minérios usados pelas indústrias desse pólo cerâmico [8]. No diagrama $\mathrm{SiO}_{2} \mathrm{vs} \mathrm{Al}_{2} \mathrm{O}_{3}$ os filitos Açungui e as ardósias, junto a duas amostras da Formação Corumbataí, destacam-se pelos teores de $\mathrm{Al}_{2} \mathrm{O}_{3}$ acima de $19 \%$ (Fig. 6A) e ficam no grupo com os menores teores de $\mathrm{SiO}_{2}(<65 \%)$.

Embora a maioria das amostras dos filitos Açungui fiquem no grupo com os maiores teores de $\mathrm{Fe}_{2} \mathrm{O}_{3}$ (entre 6 e 9\%), no geral todas as amostras variam na mesma faixa (Fig. 6B). Todas as amostras têm teores de álcalis $\left(\mathrm{Na}_{2} \mathrm{O}+\mathrm{K}_{2} \mathrm{O}\right)$ variando entre 2 e $7 \%$, sem destaque para nenhum grupo (Fig. 6C). Também no diagrama $\mathrm{Na}_{2} \mathrm{O}$ vs. $\mathrm{K}_{2} \mathrm{O}$ nenhum grupo se destaca, embora 

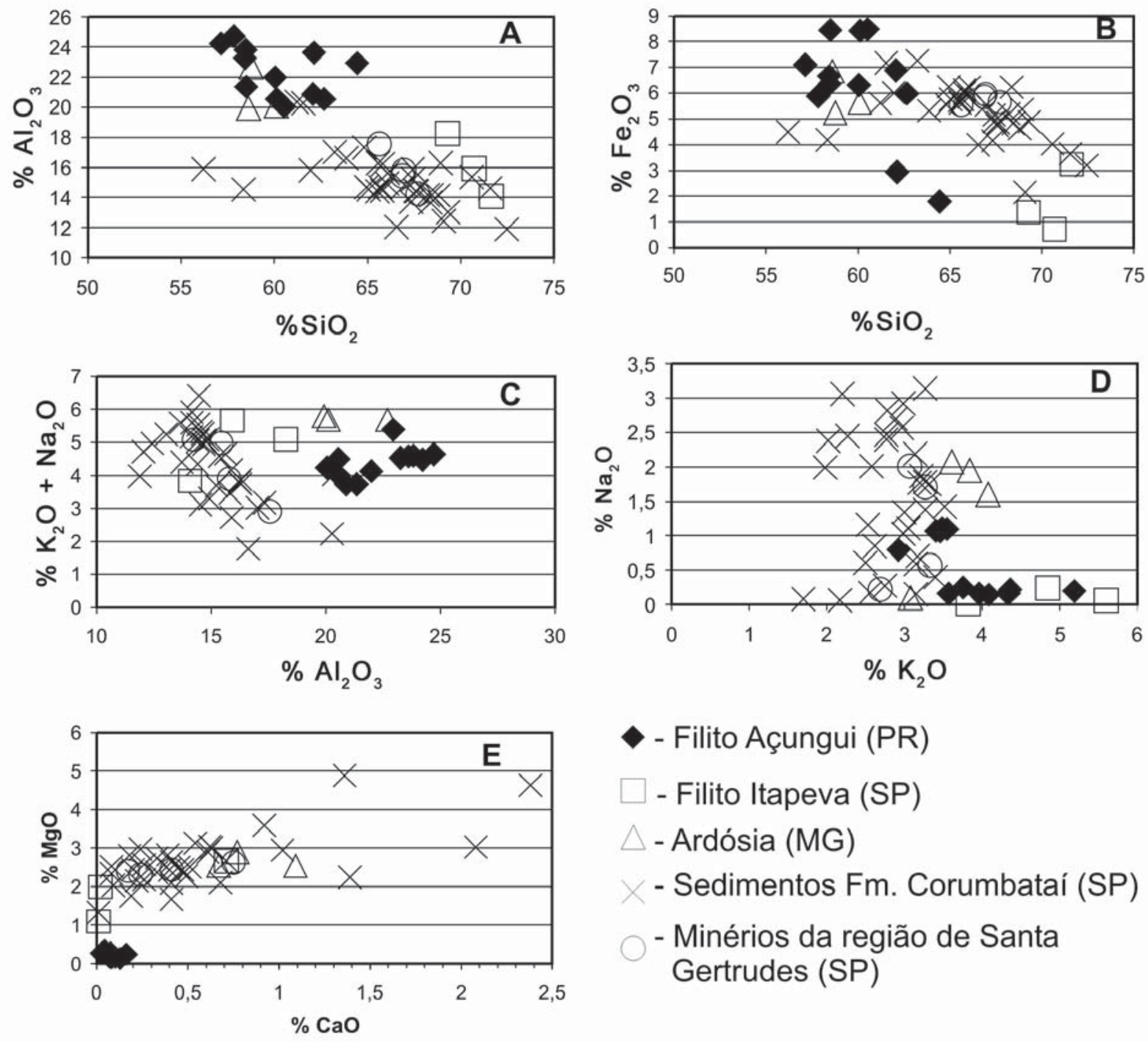

- Filito Açungui (PR)

- Filito Itapeva (SP)

- Ardósia (MG)

- Sedimentos Fm. Corumbataí (SP)

- Minérios da região de Santa Gertrudes (SP)

Figura 6: Comparação entre as composições químicas dos filitos Açungui (losângulos pretos), os filitos de Itapeva (quadrados), os sedimentos da Formação Corumbataí (cruzes), as ardósias de Minas Gerais (triângulos) e quatro tipos de minérios usados pelas indústrias da região de Santa Gertrudes (círculos). Diagramas: (A) $\mathrm{SiO}_{2}$ vs. $\mathrm{Al}_{2} \mathrm{O}_{3}$; (B) $\mathrm{SiO}_{2}$ vs. $\mathrm{Fe}_{2} \mathrm{O}_{3}$; (C) $\mathrm{K}_{2} \mathrm{O}+\mathrm{Na}_{2} \mathrm{O}$ vs. $\mathrm{Al}_{2} \mathrm{O}_{3}$; (D) $\mathrm{K}_{2} \mathrm{O}$ vs. $\mathrm{Na}_{2} \mathrm{O}$ e (E) CaO vs. $\mathrm{MgO}$.

[Figure 6: Comparison between chemical compositions of Açungui phyllites (black diamonds), Itapeva region phyllites (squares), Corumbataí Formation sediments (crosses), Minas Gerais slates (triangles) and four types of ores employed by ceramic industries of Santa Gertrudes region (circles). Diagrams: (A) $\mathrm{SiO}_{2}$ vs. $\mathrm{Al}_{2} \mathrm{O}_{3}$; (B) $\mathrm{SiO}_{2}$ vs. $\mathrm{Fe}_{2} \mathrm{O}_{3}$; (C) $\mathrm{K}_{2} \mathrm{O}+\mathrm{Na}_{2} \mathrm{O}$ vs. $\mathrm{Al}_{2} \mathrm{O}_{3}$; (D) $\mathrm{K}_{2} \mathrm{O}$ vs. $\mathrm{Na}_{2} \mathrm{O}$ e (E) $\mathrm{CaO}$ vs. $\mathrm{MgO}$.]

os filitos Açungui fiquem entre as amostras com menores teores de $\mathrm{Na}_{2} \mathrm{O}$ (Fig. 6D). Os filitos Açungui têm teores de $\mathrm{CaO}<0,2 \%$ e de $\mathrm{MgO}<0,5 \%$ e os de Itapeva têm $\mathrm{CaO}<0,1 \%$ e $\mathrm{MgO}$ entre 1,0 e 2,0\% (Fig. 6E). Esses teores são os mais baixos entre todas as amostras e indicam a ausência de smectitas e de cloritas nos filitos, cujos filossilicatos são unicamente muscovita e caulinita.

\section{Mineralogia dos filitos}

A provável existência de zeólitas nas amostras de filito Açungui coletadas nas regiões $\mathrm{C}$ e D (Figs. 1 e 2) explicaria os teores mais elevados em $\mathrm{Na}_{2} \mathrm{O}$ dessas amostras (Figs. $5 \mathrm{~A}$ e $\mathrm{B}$, Tabela I) em relação às das região B. Embora seja um mineral comum em rochas sedimentares, as zeólitas sódicas desaparecem quando reagem com sílica para formar albita, em condições de $\mathrm{Pe}$ T do início do grau metamórfico incipiente [9]. Além das zeólitas sódicas, nas mesmas condições de metamorfismo podem existir zeólitas sódico-cálcicas, dos grupos da nontronita-phillipsita-heulandita.

\section{Ensaios cerâmicos}

Temperaturas do final da fase de dilatação térmica entre 800 e $870^{\circ} \mathrm{C}$ (Figs. 4, 7A e C), a presença de patamares nas curvas de dilatação a temperaturas entre $750^{\circ}$ e $900{ }^{\circ} \mathrm{C}$ e valores de dilatação acima de $15 \mathrm{~cm} \mathrm{x} 10^{-7} /{ }^{\circ} \mathrm{C}$ diferenciam as amostras das áreas C e D daquelas da região B. Essas 

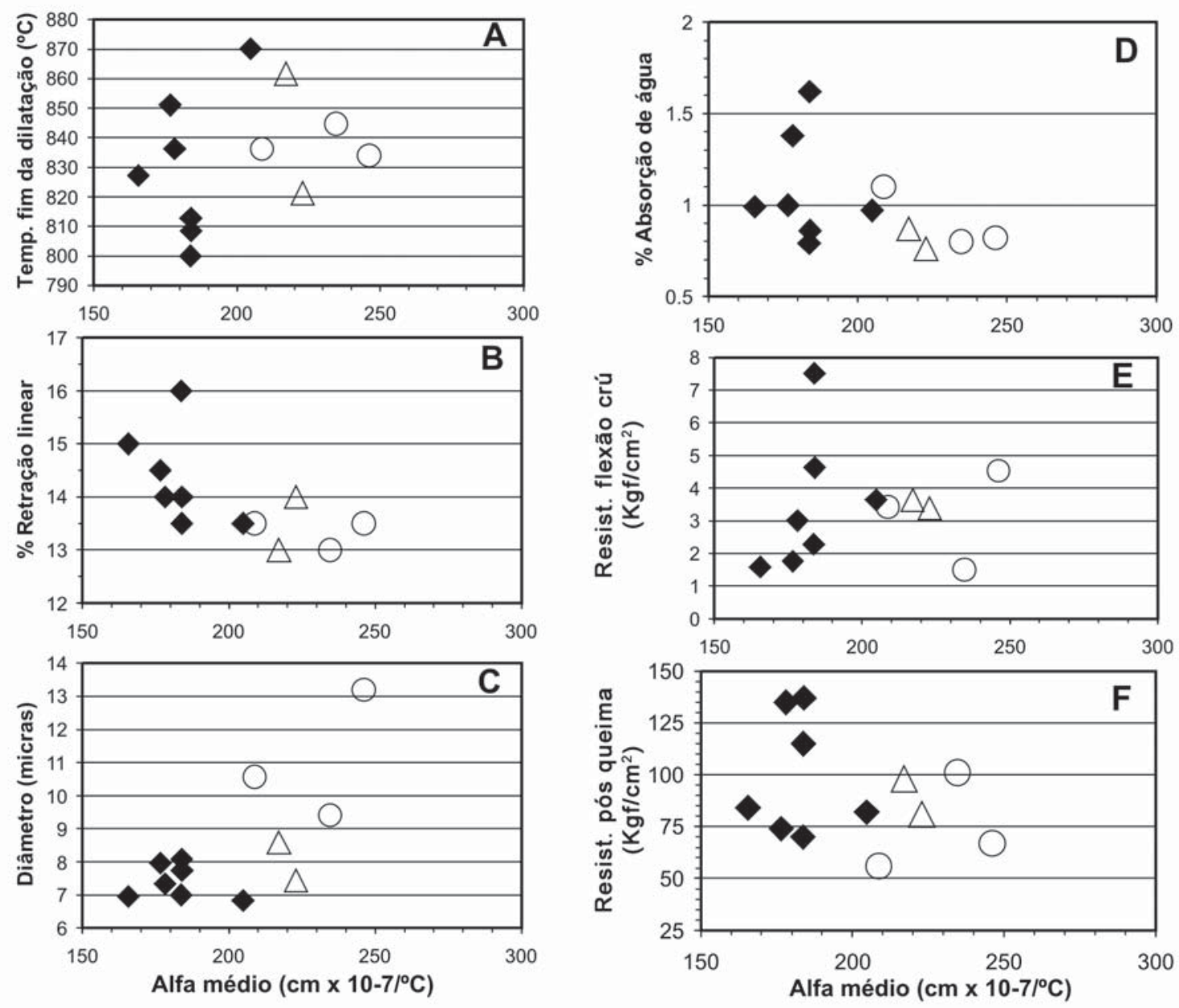

Figura 7: Propriedades cerâmicas dos filitos Açungui (PR). Valores médios de dilatação linear ( \pm ) comparados a: (A) Temperatura do final da fase de dilatação, (B) Retração linear, (C) Diâmetro médio dos grãos, (D) \% de absorção de água, (E) Resistência a flexão a cru e, (F) Resistência a flexão pós-queima a $1220^{\circ} \mathrm{C}$. Losângulos pretos $=$ filitos da região $\mathrm{B}$, triângulos $=$ região $\mathrm{C}$, círculos $=$ região $\mathrm{D}$.

[Figure 7: Ceramic characteristics of Açungui phyllites. Average stretching values ( \pm ) compared to: (A) Final temperature of stretching phase, (B) linear shrinkage, (C) Average diameter of particles, (D) Water absorption \%, (E) flexural strength before fire, $(F)$ flexural strength after $1220^{\circ} \mathrm{C}$ fire. Black diamonds $=B$ region phyllites, triangles $=C$ region phyllites and circles $=D$ region phyllites.]

características são típicas de composições micáceas [11] e indicam que os filitos dessas regiões (Fig. 1) são compostos majoritariamente por sericita/muscovita. Os da região B têm valores de dilatação a $750^{\circ}-900^{\circ} \mathrm{C}$ menores que $13,5 \mathrm{~cm} \mathrm{x}$ $10^{-7} /{ }^{\circ} \mathrm{C}$ e suas curvas de dilatação terminam com formas mais arredondadas, sem patamares (Figs. 4A e B).

Conforme já relatado, os valores de $\mathrm{D}$ separam os filitos da área $B(D<205)$ daqueles das áreas $C$ e $D(D>208)$. Além da dilatação linear, a retração linear (Fig. 7B), geralmente maior nos filitos da área $\mathrm{B}(>13,5 \%)$, e o diâmetros médios dos grãos (Fig. 7C), geralmente maiores nas áreas $\mathrm{C} \mathrm{e} \mathrm{D}(>8 \mathrm{Pm})$, diferenciam as rochas das áreas amostradas (Fig. 7A a F).

Os teores elevados de $\mathrm{K}_{2} \mathrm{O}+\mathrm{Na}_{2} \mathrm{O}$, entre 3,5 e $5,5 \%$ (Fig. 6C), e as taxas de absorção d'água muito baixas, entre 0,5 e 1,6\% (Fig. 7D), indicam que os filitos Açungui devem ser bons fundentes [10]. É notável, também, a granulometria muito fina desses filitos (Fig. 7C e Tabela III), que possibilita seu uso em materiais de acabamento, e os valores elevados, entre $13 \mathrm{e}$ $16 \%$, de retração linear pós queima a $1220^{\circ} \mathrm{C}$ (Fig. 7B e Tabela III), que torna problemático o seu uso em quantidades importantes nas massas cerâmicas.

\section{Correlações entre propriedades químicas e físicas}

Foram testadas todas as possibilidades de correlação entre teores, propriedades cerâmicas e teores vs. propriedades cerâmicas. Os resultados foram: (a) As amostras de filitos com cores próximas ao amarelo claro têm teores de $\mathrm{Fe}_{2} \mathrm{O}_{3}$ menores que $3,0 \%$ (Tabela III, segunda a quinta colunas). As cores mais escuras correspondem a teores de ferro $\leq 5,99 \%$, mas não há relação evidente entre o teor de ferro dos filitos e alguma outra cor da rocha "in natura" ou pulverizada. 

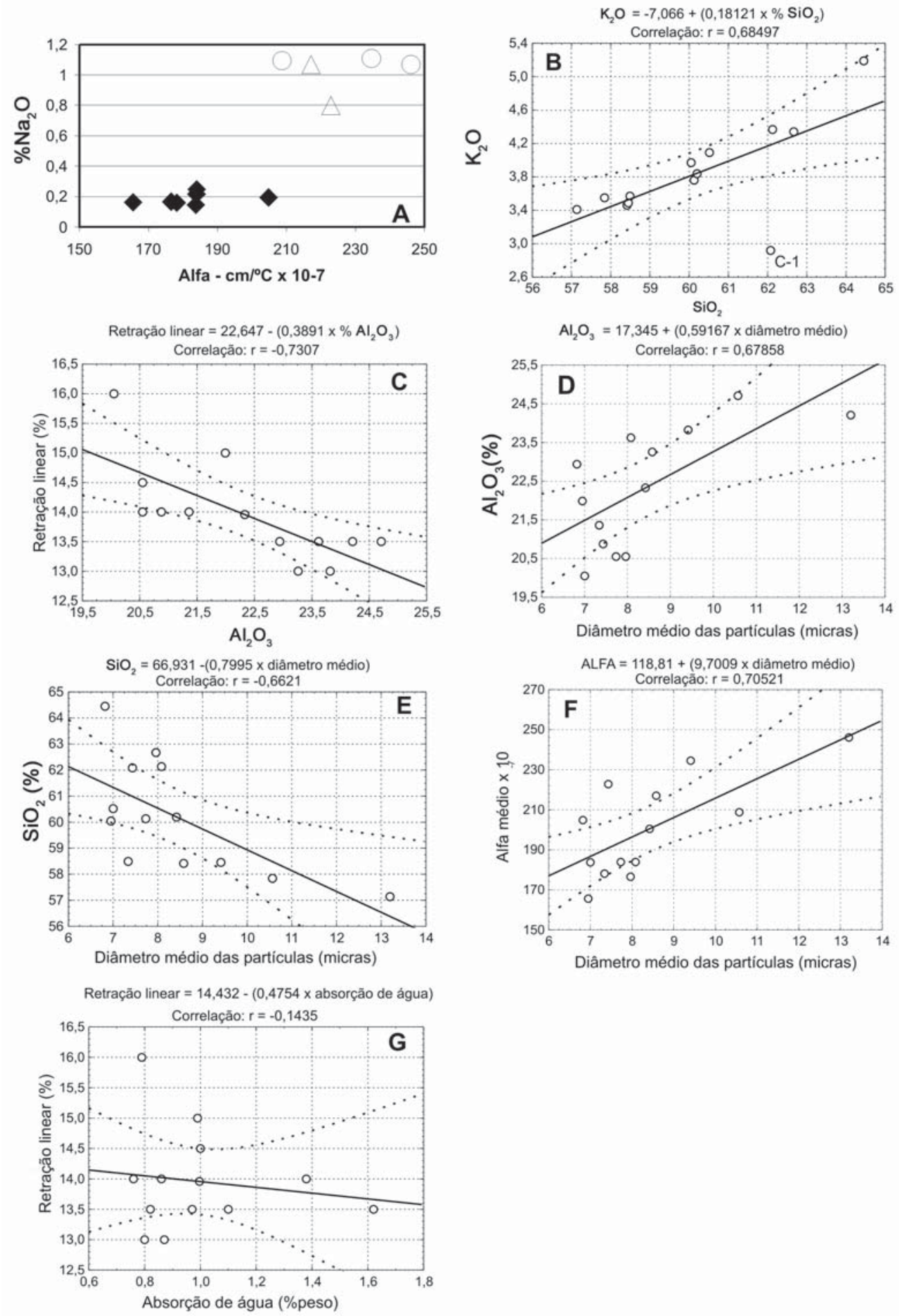

Figura 8: Correlações entre propriedades físicas e químicas dos filitos Açungui (PR). (A) Diagrama \% $\mathrm{Na}_{2} \mathrm{O}$ vs. Coeficiente de dilatação média. Nesta figura, os losângulos pretos correspondem a amostras da região B (Fig. 1), os triângulos são de amostras da região C e os círculos são de amostras da região D. Correlação entre: (B) $\% \mathrm{SiO}_{2}$ vs. $\% \mathrm{~K}_{2} \mathrm{O}$; (C) $\% \mathrm{Al}_{2} \mathrm{O}_{3}$ vs. Retração linear; (D) Diâmetro médio das partículas vs. $\% \mathrm{Al}_{2} \mathrm{O}_{3}$; (E) diâmetro médio das partículas vs. \% $\mathrm{SiO}_{2} ;$ (F) Diâmetro médio das pratículas vs. Coeficiente de dilatação média e (G) \% Absorção de água vs. \% Retração linear. As linhas pontilhadas limitam o espaço com $95 \%$ de confidência. Acima de cada figura está a equação da reta de correlação e o índice $r$ de correlação.

[Figure 8: Correlation between chemical and physical characteristics of Açungui phyllites. (A) $\mathrm{Na}_{2} \mathrm{O}$ vs. Average stretching index ( \pm ) In this figure, black diamonds $=\mathrm{B}$ region, triangles $=\mathrm{C}$ region and circles $=\mathrm{D}$ region phyllites. Correlation between: $(\mathrm{B}) \% \mathrm{SiO} \mathrm{V}_{2} \mathrm{vs}$. $\mathrm{K}_{2} \mathrm{O}$; (C) $\% \mathrm{Al}_{2} \mathrm{O}_{3}$ vs. Linear shrinkage. (D) Average particle diameters vs. \% $\mathrm{Al}_{2} \mathrm{O}_{3} ;(\mathrm{E})$ Average particle diameters vs. \% SiO $\mathrm{O}_{2}$ ( $\left.\mathrm{F}\right) \mathrm{Average}$ particle diameters Average shrinkage index, and $(G) \%$ Absorption of water vs. \% Linear stretching. Dashed lines are $95 \%$ confidence limits. The correlation equation and the respective correlation index $(r)$ is on the top of each figure.] 
(b) As propriedades que melhor diferenciam os filitos Açungui da região $\mathrm{B}$ daqueles das regiões $\mathrm{C}$ e $\mathrm{D}$ são: os teores de $\mathrm{Na}_{2} \mathrm{O}$ maiores que $0,8 \%$ nas amostras da área $\mathrm{C}$ e $\mathrm{D}$ e menores que $0,25 \%$ nas áreas C e D (Figs. $5 \mathrm{~A}$ e $8 \mathrm{~A}$ ), o valor do índice $\alpha$, maior que $205 \mathrm{~cm} \mathrm{\times} 10^{-7} /{ }^{\circ} \mathrm{C}$ nas regiões $\mathrm{C}$ e D e menor na região B (Figs. 4, 7 e 8A) e a presença de zeólitas em amostras das áreas C e D (Fig. 2). (c) Com exceção da amostra C-1, os teores de $\mathrm{SiO}_{2}$ correlacionam-se diretamente $(\mathrm{r}=0,68)$ com os de $\mathrm{K}_{2} \mathrm{O}$ (Fig. 8B). Sem a amostra C-1, a correlação sobe para 0,97 . É possível que esta correlação seja explicada pelo fato de, durante a sedimentação da bacia Açungui, ter havido aporte de quartzo, caulinita e mica detríticos, provenientes da mesma área fonte. Como a granulometria desses minerais era muito fina, o aporte teria ocorrido com proporção constante, ou seja, quanto mais quartzo foi depositado (mais $\mathrm{SiO}_{2}$ ), mais mica $\left(\right.$ mais $\mathrm{K}_{2} \mathrm{O}$ ) e caulinita foram, também, depositadas, gerando a correlação determinada na Fig. 8B. Nesse caso seria, também, necessário que durante a recristalização metamórfica a proporção original desses minerais tenha sido mantida em cada região da bacia de sedimentação. (d) $\mathrm{O}$ teor de $\mathrm{Al}_{2} \mathrm{O}_{3}$ dos filitos correlacionase inversamente $(r=-0,73)$ com a \% de retração linear pósqueima a $1220^{\circ} \mathrm{C}$ (Fig. 8C). A quantidade de mica + caulinita da rocha é diretamente proporcional ao teor de $\mathrm{Al}_{2} \mathrm{O}_{3}$, logo quanto mais mica e caulinita tiver a rocha menor é a quantidade de quartzo, as expansões geradas pelas transformações quartzo $\alpha \rightarrow$ quartzo $\beta$ (a $573{ }^{\circ} \mathrm{C}$ ) e cristobalita $\alpha \rightarrow$ cristobalita $\beta$ (entre 870 e $1470{ }^{\circ} \mathrm{C}$ ) serão pouco expressivas [11], formarse-á mais mulita [11) e a retração linear da rocha será menor. (e) $\mathrm{O}$ diâmetro médio das partículas dos filitos correlacionase diretamente $(\mathrm{r}=0,68)$ com o teor de $\mathrm{Al}_{2} \mathrm{O}_{3}$ (Fig. 8D) e inversamente $(\mathrm{r}=-0,66)$ com os de $\mathrm{SiO}_{2}$ (Fig. 8E). Provavelmente estas correlações são, também, devidas a maior quantidade de cristais de sericita (e caulinita?) que de quartzo contidos nas amostras. (f) $\mathrm{O}$ diâmetro médio correlaciona-se diretamente $(\mathrm{r}=0,70)$ também com o coeficiente $\alpha$ de dilatação (Fig. 8F), dado que as partículas maiores devem ser de sericita, que têm coeficientes de dilatação maiores (Figs. 4A e C). (g) A Fig. 8G mostra que não há correlação entre a \% de absorção de água e a retração linear das amostras. Normalmente esta correlação deveria ser inversa, dado que quanto mais o corpo de prova se contrai, menor sua porosidade e menor a sua capacidade de absorver água. Não foi encontrada uma explicação para esta ausência de correlação.

\section{CONCLUSÕES}

Os filitos Açungui são rochas muito comuns que afloram em uma área de cerca de $800 \mathrm{Km}^{2}$, em regiões de fácil acesso, a leste dos Estados do Paraná e São Paulo. Suas cores "in natura" e de queima são geralmente escuras (marron a marronavermelhado), e são mais escuras quanto maiores forem os teores de $\mathrm{Fe}_{2} \mathrm{O}_{3}$. Somente as fácies amareladas $\left(\mathrm{Fe}_{2} \mathrm{O}_{3}<3,0 \%\right)$ têm cores de queima claras, em tons de creme. Seus teores de $\mathrm{Na}_{2} \mathrm{O}+\mathrm{K}_{2} \mathrm{O}$ variam entre 2 e $7 \%$, os de $\mathrm{CaO}$ são $<0,2 \%$ e os de $\mathrm{MgO}$ são $<0,5 \%$, são compostos essencialmente por sericita, caulinita, quartzo e goethita. Zeólitas sódicas ocorrem em algumas regiões, fazendo subir o teor de $\mathrm{Na}_{2} \mathrm{O}$ das rochas de cerca de $0,2 \%$ para cerca de $1,0 \%$ e aumentando o coeficiente de dilatação linear (D) de menos de $205 \mathrm{~cm} \mathrm{x} 10^{-7} /{ }^{\circ} \mathrm{C}$ para valores entre 205 e $246 \mathrm{~cm} \mathrm{x} 10^{-7 /}{ }^{\circ} \mathrm{C}$. Os diâmetros médios das partículas dos filitos após desagregação em moinho de jarra é pequeno, variando entre 7,0 e 13,2 $\mu \mathrm{m}$, o que possibilita seu uso como material de acabamento. Os corpos de prova queimados a $1220{ }^{\circ} \mathrm{C}$ são pouco porosos, com absorção de água entre 0,8 e 1,6\%. Considerando todas as análises feitas é possível separar os filitos do Açungui em dois tipos: (a) os com teores de $\mathrm{Na}_{2} \mathrm{O}$ maiores que $0,8 \%, \alpha$ maiores que $205 \mathrm{~cm}$ x $10^{-7} /{ }^{\circ} \mathrm{C}$ e com zeólitas e, (b) os com menos que $0,25 \%$ de $\mathrm{Na}_{2} \mathrm{O}, \alpha$ menores que $205 \mathrm{~cm} \times 10^{-7} /{ }^{\circ} \mathrm{C}$ e sem zeólita. As cores de queima escuras, os elevados índices de dilatação associados aos também elevados índices de retração (entre 13 e 16\%) e baixos índices de resistência mecânica à flexão pósqueima (entre 70 e $137 \mathrm{kgf} / \mathrm{cm}^{2}$ ) limitam muito o uso dessas rochas em massas cerâmicas, onde poderiam ser aproveitadas somente como fundentes.

\section{REFERÊNCIAS}

[1] L. C. Tanno, J. F. M Motta, Cerâmica Industrial 5, 3 (2000) 37 [2] H. G. Riela, E. U. C. Franjndlich, M. Durazzo, Cerâmica Industrial 7, 3 (2002) 33.

[3] J. F. M. Motta, M. Cabral Jr., L. C. Tanno, A. Zanardo, Cerâmica Industrial 7, 1 (2002) 33.

[4] A. P. Ribeiro, L. Soares, A. V. C. Coelho, S. M. Toffoli, F. R. R. V. Diaz, Anais do $44^{\circ}$ Cong. Bras. Cerâm., S. Pedro (2000) cd-rom 04901.

[5] M. C. A. Oliveira, E P. Rodrigues, A. C. Artur, Anais do 44 ${ }^{\circ}$ Cong. Bras. Cerâm., S. Pedro (2000) cd-rom 07401.

[6] M. M. T. Moreno, S. R. Christofoletti, J. V. Valarelli, Cerâmica Industrial 5, 4 (2000) 47.

[7] M. R. Masson, S. R. Cristofoletti, H. R. Thomazella, A. Fugie, A. Zanardo, V. Alegre, Cerâmica Industrial 5, 6 (2000) 24.

[8] A. C. Fernandes, P. E. Campos e Souza, P. R. Santana, M. M. T. Moreno, S. G Carvalho, Cerâmica Industrial 3, 4-6 (1998) 24.

[9] H. G. F. Winkler, Petrogênese das Rochas Metamórficas,

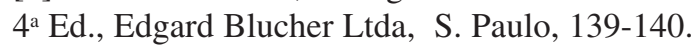

[10] L. Sánchez-Munhoz, S. da S. Cava, C. A. Paskocimas, E. Cerisuelo, E. Longo, J. B. Carda, Cerâmica 48, 306 (2002) 111. [11] A. Barba, C. Feliu, J. Garcia, F. Ginés, E. Sánchez, V. Sanz, Matérias Primas para la Fabricación de Suportes de Baldosas Cerâmicas, AICE, Instituto de Tecnologia Cerâmica, Castellón, Espanha, p.113-114 e 269.

(Rec. 03/07/03, Ac. 31/10/03) 